\title{
In vitro and in vivo effect of human lactoferrin on glioblastoma growth
}

\author{
Antonietta Arcella, PhD, ${ }^{1}$ Maria Antonietta Oliva, BSC, ${ }^{1}$ Sabrina Staffieri, BSC, ${ }^{1}$ Silvia Alberti, PhD, ${ }^{1}$ \\ Giovanni Grillea, MD, ${ }^{1}$ Michele Madonna, PhD, ${ }^{1}$ Marcello Bartolo, MD, ${ }^{1}$ Luigi Pavone, PhD, ${ }^{1}$ \\ Felice Giangaspero, MD, ${ }^{1,2}$ Giampaolo Cantore, MD, ${ }^{1}$ and Alessandro Frati, MD, PhD, ${ }^{1,2}$
}

\author{
${ }^{1}$ IRCCS Neuromed, Località Camerelle, Pozzilli; and 2University of Rome La Sapienza, Rome, Italy
}

\begin{abstract}
OBJECT Human lactoferrin (HLF) is a natural protein with antitumor activity. The aim of this study was to investigate the effects of HLF alone and in combination with temozolomide (TMZ), a conventional chemotherapeutic, on human glioblastoma (GBM) cells.

METHODS The authors cultured fresh human primary cell lines NMD and FN and the continuous cell line U87MG to evaluate proliferation in the presence of HLF alone at different doses $(1,10$, and $100 \mu \mathrm{g} / \mathrm{ml}$, and $1 \mathrm{mg} / \mathrm{ml})$ and in combination with TMZ. In in vivo experiments they assessed tumor size reduction in CD1 nude mice carrying an orthotopic GBM xenograft and orally treated with HLF.
\end{abstract}

RESULTS Lactoferrin causes growth inhibition in the NMD and FN primary cell lines and in the U87MG continuous cell line. This inhibition seemed to be modulated by the downregulation of cyclin D1 and D4. Western blot and fluorescenceactivated cell sorting analysis showed inhibition of the cell cycle in G0/G1 and G2 phases. When administered in nude mice, HLF (60 mg/kg/day) decreased tumor size about 30\%, as shown in both histological analyses and high-field brain MRI. Administration of HLF with TMZ enhanced the effect of chemotherapy both in vitro and in vivo.

CONCLUSIONS This study demonstrated that HLF can inhibit GBM cell growth, suggesting that this nontoxic substance may have a role in potentiating the effect of current TMZ treatment of GBM.

http://thejns.org/doi/abs/10.3171/2014.12.JNS14512

KEY WORDS glioblastoma; human lactoferrin; glioblastoma xenografts; human glioblastoma primary cultures; oncology

$\mathrm{G}$ Lioblastoma (GBM) is the most common malignant brain tumor in adults and remains incurable despite aggressive treatment. Significant efforts have been made to identify molecular pathways and genes involved in gliomagenesis ${ }^{14,19}$ and to find novel therapeutic targets..$^{22}$ Thus far, however, the standard treatment for GBM has been radiotherapy associated with temozolomide (TMZ) chemotherapy. To discover new substances that can improve the standard GBM treatment, we have focused our attention on human lactoferrin (HLF), a natural agent with no toxicity ${ }^{16}$ that has been shown to inhibit both the development of experimental metastases ${ }^{4}$ in mice and the growth of intestinal, head, and neck cancer in an in vitro human cancer cell model. . $^{8,30}$ This negative effect of HLF on cell proliferation may be ascribed to the altered expression or activity of regulatory proteins. ${ }^{6}$
Lactoferrin-dependent, cytokine-mediated stimulation of the activity of natural killer (NK) cells and CD4+ and CD8+ lymphocytes represents an important factor in the defense against tumor growth. There are more of these cells in both the blood and the lymphatic tissue after the oral administration of HLF. Smaller concentrations of HLF $(10 \mu \mathrm{g} / \mathrm{ml})$ stimulate the cytolysis of tumor cells, whereas cytolysis seems to depend on the cell phenotype at higher concentrations $(100 \mu \mathrm{g} / \mathrm{ml}){ }^{7}$ Lactoferrin-mediated inhibition of tumor growth may be related to apoptosis of these cells induced by the activation of the Fas signaling pathway; however, the exact mechanism of this function has not been discovered as yet. ${ }^{11}$

Documented studies have shown that HLF also significantly reduces the development of various neoplasms such as esophageal, lung, bladder, and colon cancer., ${ }^{928}$ Interest-

\footnotetext{
ABBREVIATIONS bLF = bovine lactoferrin; BrdU = bromodeoxyuridine; BSA = bovine serum albumin; DMEM = Dulbecco's modified Eagle's medium; FACS $=$ fluores cence-activated cell sorting; FCS = fetal calf serum; FRFSE = fast-recovery fast spin-echo; GBM = glioblastoma; HLF = human lactoferrin; NK = natural killer; PBS = phosphate-buffered saline; TMZ = temozolomide.

SUBMITTED March 11, 2014. ACCEPTED December 11, 2014. INCLUDE WHEN CITING Published online July 17, 2015; DOI: 10.3171/2014.12.JNS14512.

DISCLOSURE The authors report no conflict of interest concerning the materials or methods used in this paper or the findings specified in this paper. This research was supported by the Italian Ministry of Education, Universities, and Research, through PRIN Prot. 2010ZESJWN_006.
} 
ingly, HLF has also been very effective in suppressing the growth of pancreatic cancer cells. Lactoferrin could become a new drug of choice for supportive therapy against pancreatic cancer cells in vitro. ${ }^{23}$ So far no studies have investigated the effect of HLF on glioma cells. The aim of this study was to explore the effects of HLF on human GBM cell lines in vitro and in mice xenografts.

\section{Methods}

\section{Materials}

We used 3 human GBM cell lines: 2 primary cell lines (NMD and FN) prepared directly from biopsy specimens from patients (from Neuromed Neurosurgery) and a continuous cell line (U87MG, American Type Culture Collection). For both in vitro and in vivo treatments we used HLF (Bioscience) and TMZ (Sigma). For protein analysis we used the following antibodies: mouse monoclonal antibody anti-cyclin D1, mouse monoclonal antibody anticyclin D4, and rabbit polyclonal antibody anti-pERK1/2 (all Cell Signaling).

\section{Cell Cultures}

The U87MG human GBM continuous cell line and the NMD and FN human GBM primary cell lines were grown in Dulbecco's modified Eagle's medium (DMEM) supplemented with $10 \%$ fetal calf serum (FCS; Invitrogen) in culture dishes (Becton Dickinson) at $37^{\circ} \mathrm{C}$ in $5 \% \mathrm{CO}_{2}$ and 95\% humidity. The medium was changed every 3 days.

\section{Human Lactoferrin Treatment of Human GBM Cell Lines}

To evaluate the in vitro response to treatment with HLF, we plated human GBM cells (U87MG, NMD, and $\mathrm{FN}$ ) in 24-well plates at $2.5 \times 10^{3}$ cells per well in DMEM supplemented with $10 \%$ FCS and incubated them at $37^{\circ} \mathrm{C}$ in an atmosphere containing $5 \% \mathrm{CO}_{2}$. The following day the cells were treated (every 24 hours for 5 days) with HLF at the following concentrations: 1,10 , and $100 \mu \mathrm{g} / \mathrm{ml}$, and $1 \mathrm{mg} / \mathrm{ml}$. At 1,3, and 5 days after HLF treatment, a cell count was made using a Bürker chamber and trypan blue dye (Sigma) to discriminate live cells from dead.

\section{Combined Treatment of Human GBM Cell Lines}

To evaluate the in vitro response to combined HLF and TMZ treatment, we plated human GBM cells (U87MG, NMD, and FN) under the same cell growth conditions as in the first experiment. The GBM cells were seeded in 96-well plates (5000 cells/well) and were treated every 24 hours for 5 days with TMZ at $1 \mu \mathrm{M}$ alone or in combination with $\mathrm{HLF}$ at $10 \mu \mathrm{g} / \mathrm{ml}$. At 1,3, and 5 days after treatment, a cell count was performed.

\section{Analysis of Cell Cycle Proteins After Treatment With HLF}

Proteins were extracted from the HLF-treated $(10 \mu \mathrm{g} /$ $\mathrm{ml}$ ) U87MG and NMD cells in Triton X-100 lysis buffer (Tris-HCL $10 \mathrm{mM}$, EDTA $1 \mathrm{mM}, \mathrm{NaCl} 150 \mathrm{mM}$, Triton $\mathrm{X}-100$ 1\%, Naf $1 \mathrm{mM}$, Na4P2O7 $1 \mathrm{mM}$, Na3VO4 $1 \mathrm{mM}$, and protease inhibitors $1 \times)$. Proteins $(40 \mu \mathrm{g})$ were separated by sodium dodecyl sulfate polyacrylamide gel electrophoresis (SDS-PAGE) on a $12.5 \%$ polyacrylamide gel and were transferred to nitrocellulose membranes by electroblotting. The membranes were incubated for 2 hours at room temperature in 5\% milk diluted in $1 \times$ Tris-buffered saline containing Tween-20 and then incubated overnight at $4^{\circ} \mathrm{C}$ with primary antibodies specific for cyclin D1 and D4 and ERK1/2, and 1 hour with a secondary antibody. Each membrane was then incubated with mouse monoclonal anti- $\beta$-actin (1:10000, Santa Cruz Biotechnology). The proteins were detected by chemiluminescence using ECL Western blotting (Amersham). Signals were detected by a digital scanner and quantified by densitometric analysis (Scion Image software).

For cyclin D1 and D4 analysis, cells were plated at a density of 500,000 cells per plate in DMEM without FCS for 48 hours. After re-adding 10\% FCS, induction was performed with HLF $(10 \mu \mathrm{g} / \mathrm{ml})$ for 2,4 , and 8 hours; anti-cyclin D1 and anti-cyclin D4 antibody (1:1000, Cell Signaling) were used. For pERK1/2 detection, treatments with HLF $(10 \mu \mathrm{g} / \mathrm{ml})$ were performed at 10 minutes, 30 minutes, 2 hours, and 4 hours. The membranes were incubated overnight with anti-pERK1/2 antibody (1:1000, Cell Signaling) in $2.5 \%$ bovine serum albumin (BSA).

\section{Bromodeoxyuridine Incorporation and Cell Cycle Analysis by Flow Cytometry}

The U87MG human GBM cells were plated $\left(10^{6}\right)$ in DMEM with $10 \%$ FCS and treated with recombinant HLF $(10 \mu \mathrm{g} / \mathrm{ml})$ or phosphate-buffered saline (PBS) solution (controls) for 24, 48, and 72 hours. Before analysis, $10 \mathrm{mM}$ bromodeoxyuridine (BrdU; Sigma) was added to the cells; after 24 hours the cells were trypsinized, fixed in $70 \%$ ethanol, and stored at $-20^{\circ} \mathrm{C}$ until the day of analysis. Cells were incubated in $2 \mathrm{M} \mathrm{HCl}$ for 30 minutes and then in 0.1 $\mathrm{M}$ sodium borate, $\mathrm{pH} 8.5$, for 2 minutes. Samples were resuspended in dilution buffer (1× PBS, 0.5\% Tween-20, and $0.5 \% \mathrm{BSA}$ ) containing $0.3 \mathrm{mg}$ of anti-BrdU antibody (BD Bioscience) and incubated at $4^{\circ} \mathrm{C}$ for 1 hour. After incubation with anti-mouse FITC-conjugated antibody (BD Biosciences) at $4^{\circ} \mathrm{C}$ for 1 hour, propidium iodide (10 pg/ $\mathrm{ml}$ ) was added for 15 minutes. Fluorescence-activated cell sorting (FACS) analysis of the cell cycle was performed with a Coulter Elite flow cytometer (Beckman Coulter).

\section{Implantation of U87MG Cells}

For both the first and the second series of experiments, male CD1 nude mice (Charles River Laboratories; 20$22 \mathrm{~g}$ body weight) were housed in controlled conditions (temperature $22^{\circ} \mathrm{C}$; humidity $40 \%$ ) on a 12-hour light/ dark cycle with food and water ad libitum and observed daily. The experiments were performed according to the guidelines for the care and use of animals promulgated by the National Institutes of Health. The U87MG GBM cells were implanted in the caudate nucleus of the mice $(400,000$ cells per animal) using the following stereotactic coordinates: $0.6 \mathrm{~mm}$ anterior to the bregma, $1.7 \mathrm{~mm}$ lateral to the meridian line, $3.5 \mathrm{~mm}$ in depth from the surface of the skull. Animals were anesthetized intraperitoneally with ketamine $(100 \mathrm{mg} / \mathrm{kg})$ and xylazine $(10 \mathrm{mg} / \mathrm{kg})$. The cells $\left(0.4 \times 10^{6}\right.$ cells $/ 5 \mu \mathrm{l}$ DMEM without FCS $)$ were im- 
planted at an infusion rate of $1 \mu \mathrm{l} /$ minute. At 7 days after inoculation, HLF treatments $(60 \mathrm{mg} / \mathrm{kg} /$ day $)$ were orally administered for 12 days, and a group of untreated mice were used as a reference standard. At the end of treatment, the mice in the first series of experiments were submitted to high-field (3-T) brain MRI to monitor tumor growth. Subsequently, on the same day as imaging (19 days after inoculation), the mice were sacrificed by cervical dislocation after anesthesia was induced, and their brains were removed, fixed in formalin, dehydrated in ethanol at increasing concentrations, and embedded in paraffin.

From each brain, $10-\mu \mathrm{m}$-thick serial sections, sampled from the beginning of the striatum to the hippocampus (1 section every $400 \mu \mathrm{m}$ ), were cut. Subsequently, the sections were stained with Mayer's hematoxylin and eosin (both Diapath) and subjected to analysis for the quantification of tumor volume. The volumetric analysis was performed using software that measures the tumor area in each section and calculates the total volume of the tumor according to the Cavalieri method ${ }^{13}$ by using the following formula: $\mathrm{V}=\Sigma(\mathrm{A}) \mathrm{i} \times \mathrm{TS} \times \mathrm{n}$, where (A)i is the area of the tumor in level $i$, TS is the section thickness, and $n$ is the number of sections disposed between the 2 levels.

In the first series of experiments, at 7 days after implantation of the U87MG cells, mice $(\mathrm{n}=20)$ were subdivided into 2 groups: control group $(n=10)$ and HLF group $(n=$ 10). Treatment was orally administered daily by gavage (saline or $60 \mathrm{mg} / \mathrm{kg} \mathrm{HLF}$ ) for 12 days. Mice were analyzed using brain MRI 19 days after cell implantation.

In the second series of experiments, we tested the in vivo effect of HLF and TMZ in a nude mouse xenograft model. The CD1 mice $(\mathrm{N}=32)$ were inoculated in the caudate nucleus with 400,000 U87MG cells. One week after inoculation, mice were subdivided into 4 groups: 1) Group 1,8 control mice treated only with dimethyl sulfoxide $0.5 \%$; 2) Group 2, 8 mice treated with TMZ $(6 \mathrm{mg} /$ $\mathrm{kg} /$ day); 3) Group 3, 8 mice treated with HLF (60 mg/kg/ day); and 4) Group 4, 8 mice treated with HLF and TMZ $(60 \mathrm{mg} / \mathrm{kg} /$ day and $6 \mathrm{mg} / \mathrm{kg} / \mathrm{day}$, respectively). The drugs were orally administered 5 days per week for 3 weeks.

\section{Brain MRI}

In the first series of experiments, after 12 days of treatment with HLF, the CD1 nude mice inoculated with U87MG were monitored with MRI after anesthesia was induced using intraperitoneal ketamine $(100 \mathrm{mg} / \mathrm{kg})$ and xylazine $(10 \mathrm{mg} / \mathrm{kg})$. Magnetic resonance imaging was performed on a 3-T GE Signa HDxt scanner (GE Healthcare) equipped with a $20-\mathrm{mm}$ surface coil. We acquired T2-weighted fast-recovery fast spin-echo (FRFSE) images: TE $120 \mathrm{msec}$, TR $2940 \mathrm{msec}$, matrix size $256 \times 256$, slice thickness $2 \mathrm{~mm}$.

The total volume of each tumor was measured using a series of axial T2-weighted FRFSE sequences. Tumor volume was evaluated using Osirix software (http://www. osirix-viewer.com/), open-source software for navigating in multidimensional DICOM images. The area of the lesion was manually drawn on each imaging slice, and the total lesion volume was calculated by 2 blinded independent investigators using the software.

\section{Results}

\section{Effect of HLF on the Growth Rate of Human GBM Cells}

The effect of HLF on GBM cell proliferation was analyzed long term, with cell counts run at 1,3 , and 5 days after treatment. As shown in Fig. 1, the continuous cell line U87MG had a significant reduction in proliferation; even primary cell lines NMD and FN had a moderate reduction at 3 days of treatment with $1 \mathrm{mg} / \mathrm{ml}$ HLF and a more significant reduction at 5 days of treatment with HLF at 1 $\mu \mathrm{g} / \mathrm{ml}, 10 \mu \mathrm{g} / \mathrm{ml}$, and $100 \mu \mathrm{g} / \mathrm{ml}$. The HLF concentration that caused the greatest growth inhibition in all cell lines was $10 \mu \mathrm{g} / \mathrm{ml}$.

Lactoferrin treatment amplified the effects of TMZ on the proliferation of human glioma cells in vitro. The primary GBM cell lines FN and NMD and the continuous cell line U87MG were treated with TMZ $(1 \mu \mathrm{M})$ alone or in combination with $\operatorname{HLF}(10 \mu \mathrm{g} / \mathrm{ml})$, and after 1,3 , and 5 days, the activity of the drugs on cell count was evaluated. The TMZ treatment appeared to be effective, but a statistically significant reduction in growth was observed in cells treated with a combination of the 2 drugs as early as 24 hours after treatment (Fig. 2).

\section{Evaluating the Expression of Cell Cycle Proteins in NMD and U87MG Cells Treated With HLF}

The expression of cyclin D1 and D4 after 2, 4, and 8 hours of treatment with HLF $10 \mu \mathrm{g} / \mathrm{ml}$ was analyzed using Western blotting on samples of proteins extracted from both the continuous line U87MG and the primary line NMD. In the NMD cell line, we observed a significant reduction in cyclin D1 and D4 within 2 hours after HLF treatment compared with the control sample (untreated cells; Fig. 3A). The U87MG, however, showed a significant reduction in only cyclin D4 within 2 hours of treatment (Fig. 3B). These differences between the primary cell line and continuous cell line are supported by their different proliferative rates; that is, the continuous line grows more quickly. The reduction of cyclin D1 and D4 is an early event in the cell cycle. This is why the reduction is evident after just 2 hours of treatment with HLF. After 2 hours of induction, cyclin D1 and D4 reach a steady state and the inhibition induced by HLF is no longer visible.

The results suggest that HLF blocks the cellular cycle in the G0/G1 phase in which the cyclins D1 and or D4 are specifically involved. On the other samples of proteins extracted at different times (10 minutes, 30 minutes, 2 hours, and 4 hours; after treatment with $10 \mu \mathrm{g} / \mathrm{ml} \mathrm{HLF}$ ), we evaluated the phosphorylation of ERK1 and ERK2. In the primary cell line NMD, HLF significantly reduced the pERK1 and pERK2 at both 10 and 30 minutes after treatment. Even in U87MG, there was a reduction in the pERK1 and pERK 2 only within 2 hours of treatment (Fig. 4). We used different time courses for cyclin analysis and pERK detection because phosphorylation is an event with an even earlier protein turnover.

\section{Cell Cycle Analysis}

Cell cycle FACS analysis in U87MG cells treated with HLF for 24, 48, and 72 hours showed a significant reduction in the percentage of cells in the $S$ phase of the cell 


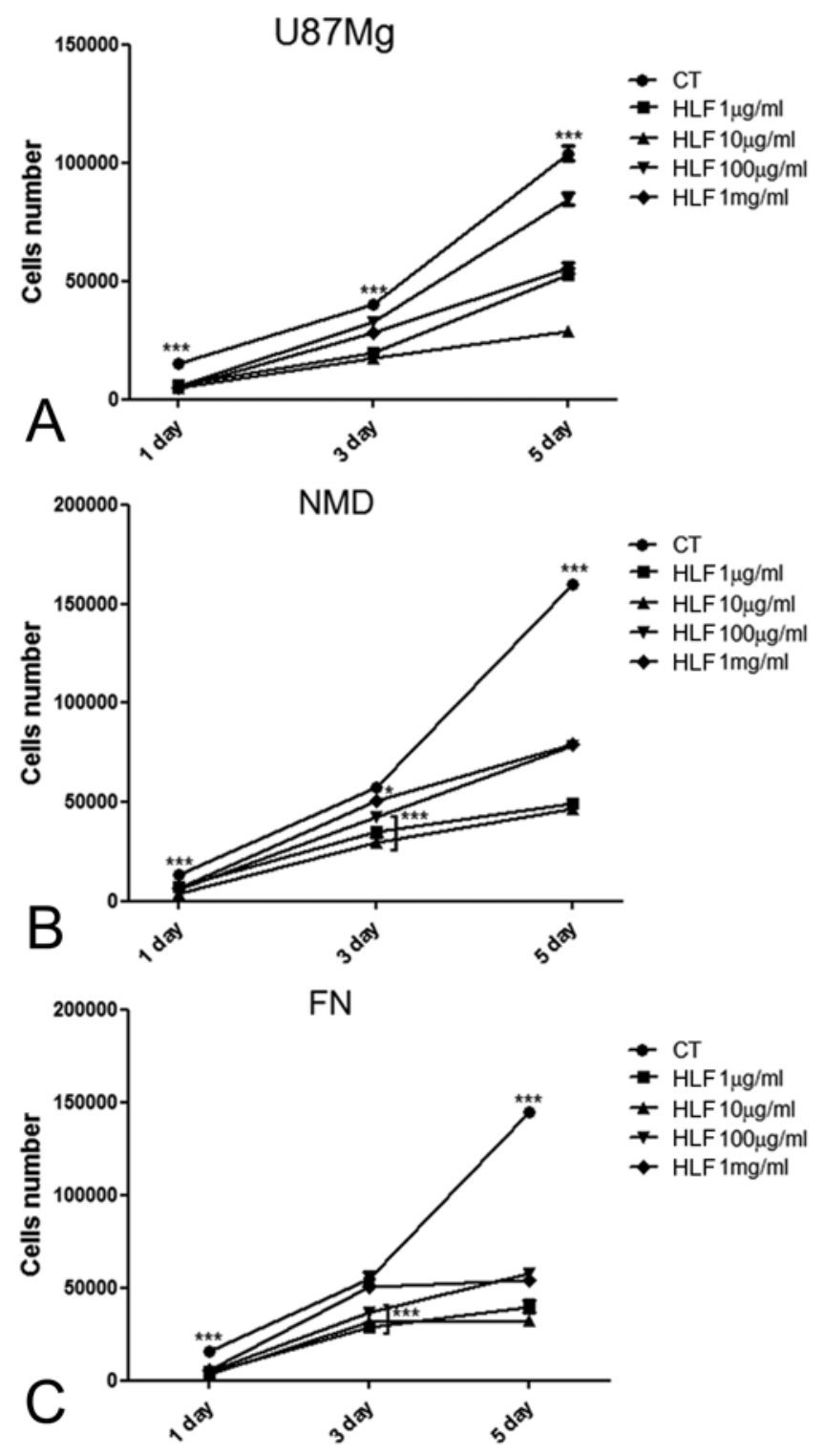

FIG. 1. Exposure of the continuous U87MG GBM cell line and NMD and FN primary cell lines to HLF. Human lactoferrin $(1 \mathrm{mg} / \mathrm{ml}$ and 1,10 , and $100 \mu \mathrm{g} / \mathrm{ml}$ ) reduced U87MG, NMD, and FN cell growth in culture. Drug was applied to the cultures every 24 hours for 5 days. Values are the means \pm the standard error of the mean (SEM) of 3 individual determinations. ${ }^{*} p<0.05$ (1-way ANOVA). ${ }^{* *} p<0.001$. CT $=$ control.

cycle that was associated with an increased percentage of cells in the G0/G1 and $\mathrm{G} 2$ phases, compared with that in the vehicle-treated U87MG cells. This was associated with a decreased percentage of cells incorporating BrdU, which are otherwise abundant in vehicle-treated cell cultures (Fig. 5 and Table 1). Even in primary cell cultures (NMD) from a patient, the percentage of cells in the $\mathrm{S}$ phase and BrdU incorporation were markedly reduced by HLF administration (data not shown).

\section{In Vivo Experiments}

In the first series of experiments, we implanted U87MG cells into the left caudate nucleus of nude mice. The MRI

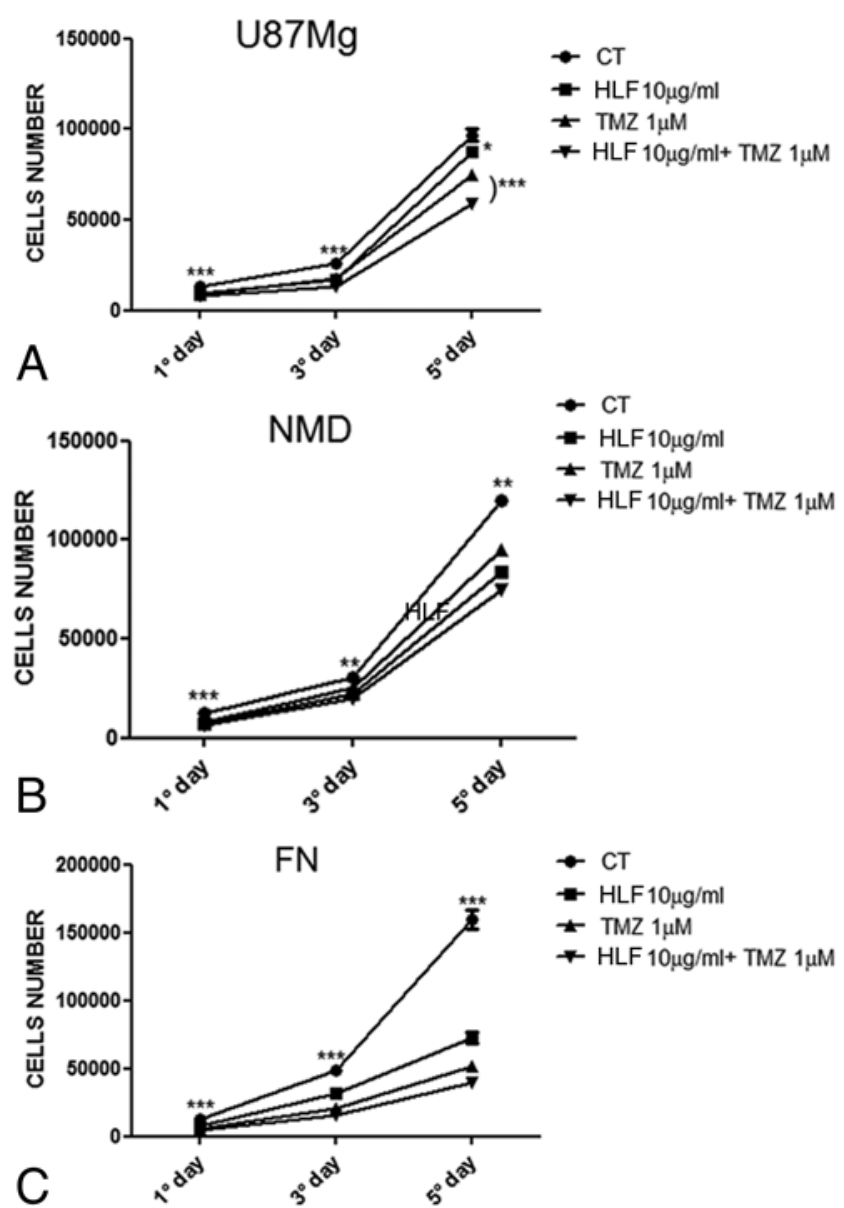

FIG. 2. Synergistic effect of HLF and classic chemotherapy (TMZ) in U87MG, NMD, and FN GBM cells. The GBM cells were seeded in 96-well plates ( 5000 cells/well) and treated with HLF $(10 \mu \mathrm{g} / \mathrm{ml})$ alone or in combination with $1 \mu \mathrm{M} \mathrm{TMZ}$. Cell count at 1,3 , and 5 days after treatment was used to assess cell proliferation in each treatment group. Values are the means \pm SEM of 3 individual determinations. ${ }^{*} p<0.05$ (1-way ANOVA). ${ }^{* *} p<0.001 .{ }^{* * *} p<0.001$.

studies 19 days after cell implantation showed that the tumor in all HLF-treated animals $(n=10)$ was smaller than in the control group $(n=10)$ and that the margins were more defined with no edema (Fig. 6). Histological examination of brain xenografts, performed after MRI analysis, showed a homogeneous tumor mass with sharp borders, which was clearly delimited by adjacent brain tissue. Cytologically, tumors were composed of large pleomorphic cells with abundant eosinophilic cytoplasm (Fig. 7). Evaluation by volumetric analysis of slides confirmed that, in mice treated with HLF, tumor size decreased about $30 \%$.

To evaluate long-term effects of HLF and TMZ on the survival of mice carrying GBM xenograft, we conducted a second series of in vivo experiments. The Kaplan-Meier tumor curve demonstrated that HLF alone has a moderate effect on long-term survival; treated mice survived for 5 more days than the control mice (vehicle-treated; Fig. 8A). Temozolomide alone exhibited a dramatic effect on survival: treated mice died 35 days after the controls. Nonetheless, the combination of HLF and TMZ potentiates the effect of the chemotherapeutic alone; mice treated with 
A NMD
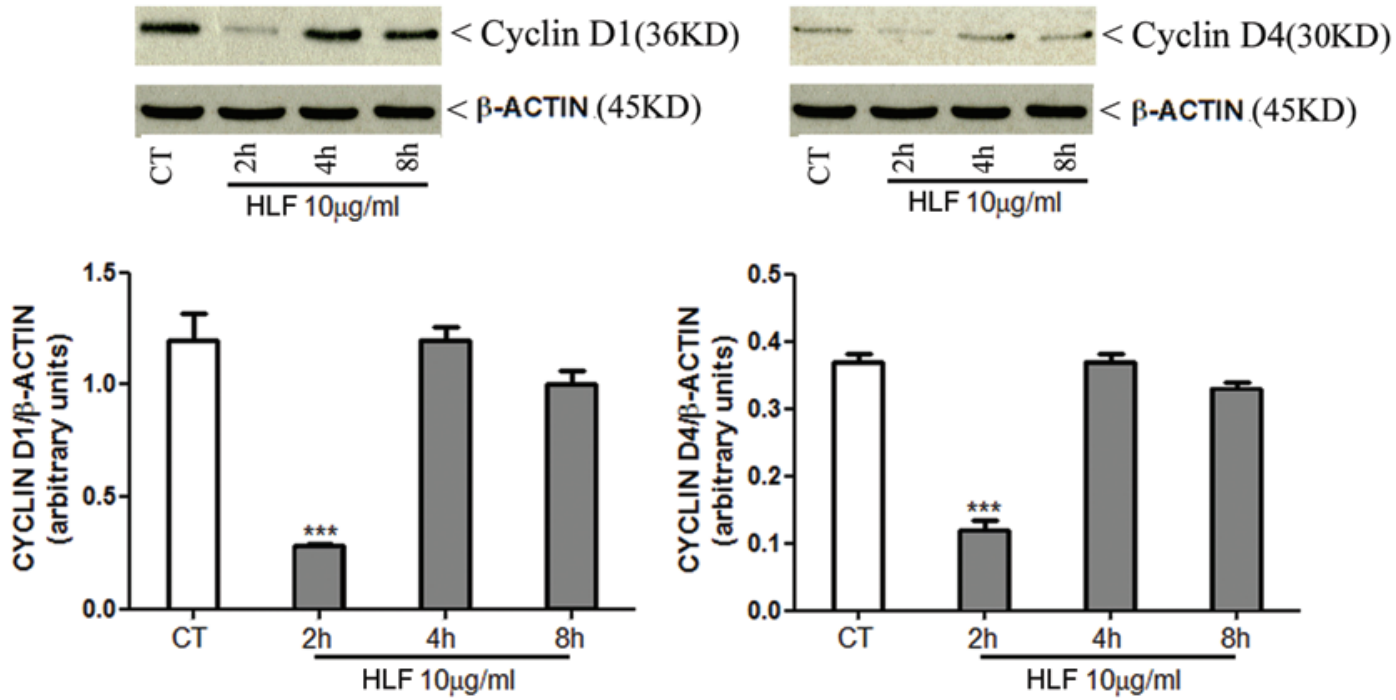

B $\quad$ U87Mg
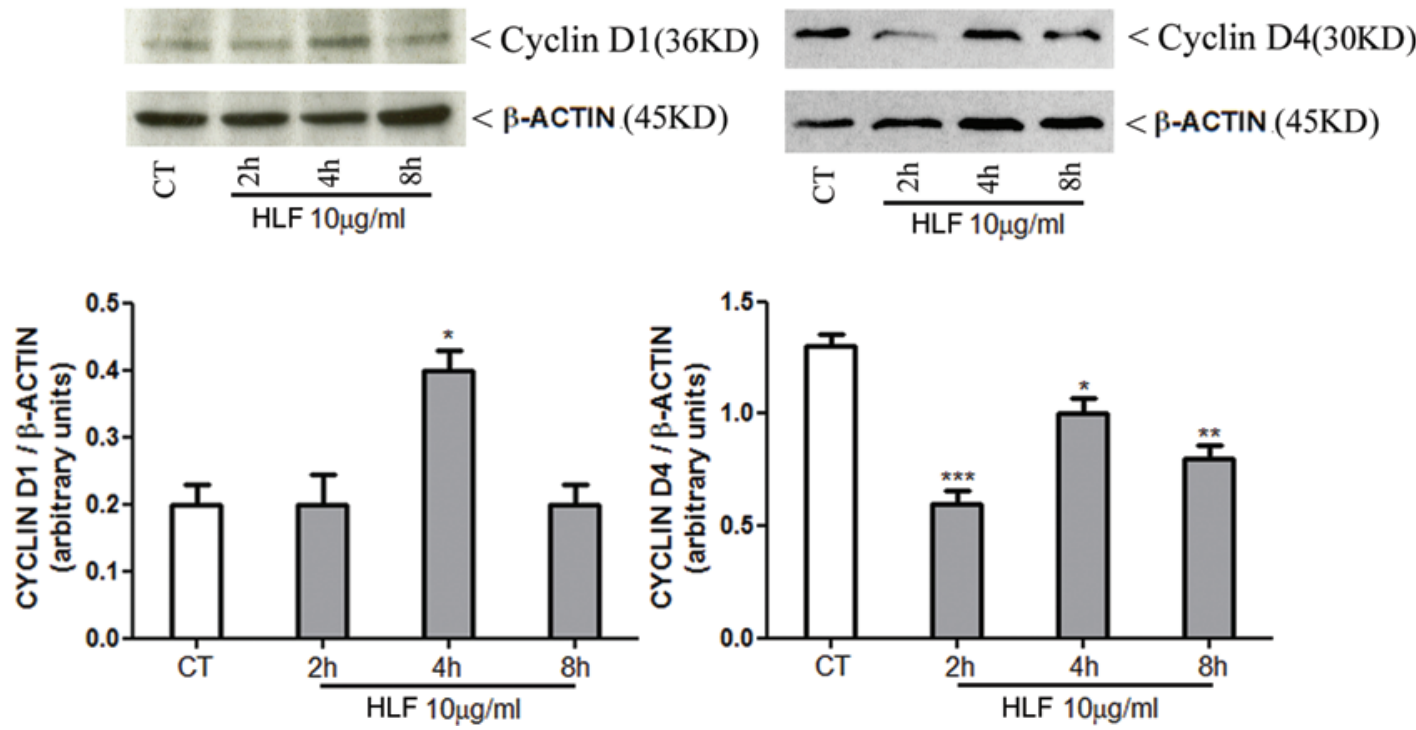

FIG. 3. Downregulation of cyclin D1 and D4 in NMD and U87MG cell lines after treatment with HLF. Western blotting and densitometric analysis of cyclin D1 and D4 in the primary GBM cell line NMD (A) and continuous GBM cell line U87MG (B) after treatment with $10 \mu \mathrm{g} / \mathrm{ml} \mathrm{HLF}$. Thirty micrograms of protein was loaded for each lane. The blot was repeated 3 times with similar results. Drug was applied to the cultures every 2, 4, and 8 hours. Values are the means \pm SEM of 3 individual determinations. ${ }^{*} p<0.05$ (1-way ANOVA and Dunnett test). ${ }^{* *} p<0.001 .{ }^{* *} p<0.0001$. Figure is available in color online only.

the drug combination survived 10 days more than those treated with TMZ alone (Fig. 8B).

\section{Discussion}

Despite the scientific progress in understanding the underlying mechanisms of drug resistance, we still do not have an effective therapy for malignant glioma. Current treatments for GBM include standard resection, radiotherapy, and chemotherapy. Despite this multimodal therapy, the prognosis of GBM remains dismal, with a median patient survival of approximately 1 year. ${ }^{26,27}$ Moreover such treatments are associated with different adverse effects that may limit a patient's quality of life. Improving the efficacy of standard treatments with nontoxic substances could benefit such a patient. Drug resistance is the major obstacle in the treatment of gliomas ${ }^{10}$ considering that surgery can result in gross-total resection of the tumor but both microscopic residual (not detectable at MRI) and cancer stem cells are always present. The treatment of glioma is projected toward the integration of nontoxic adjuvants to current therapies.

Lactoferrin has been identified in secretions from exocrine glands and in specific granules of neutrophils. After degranulation, neutrophils become the main source of LF in blood plasma. ${ }^{1}$ Lactoferrin possesses different biologi- 

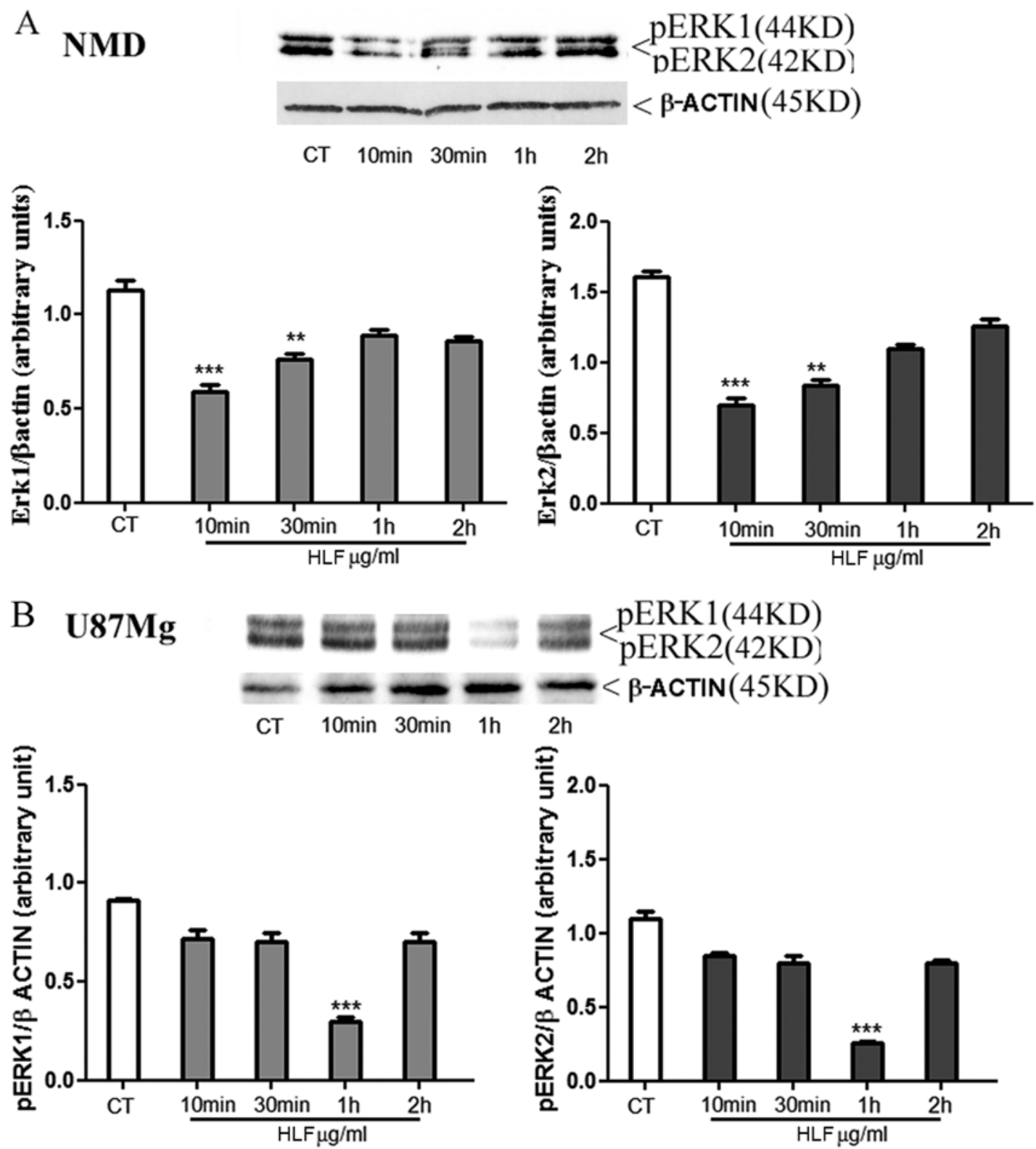

FIG. 4. Downregulation of ERK1 and ERK2 in NMD and U87MG cell line after treatment with lactoferrin. Western blot and densitometric analysis of ERK1 and ERK2 in primary glioblastoma cell line NMD (A) and continous cell line U87MG (B) after treatment with HLF $10 \mu \mathrm{g} / \mathrm{ml}$. Thirty micrograms of proteins were loaded for each lane. The blot was repeated 3 times with similar results. Drug was applied to the cultures for 10 minutes, 30 minutes, 2 hours, and 4 hours. Values are means \pm SEM of 3 individual determinations. * $p<0.05$ (1-way ANOVA and Dunnett test).

cal functions and has roles in iron metabolism, cell proliferation, differentiation, and antibacterial, antiviral, and antiparasitic activity. ${ }^{2,3,12,15,17,18,21,24,25,29,31}$ In particular, Kozu et al. demonstrated that the 1-year oral administration of $3.0 \mathrm{~g} /$ day of bovine lactoferrin (bLF) induced a statistically significant reduction in the size of a colorectal adenomatous polyp. ${ }^{17}$ Similarly, Tsuda et al. showed that the administration of bLF suppressed carcinogenesis in the colon and other organs of test animals and that the ingestion of bLF inhibited the growth of adenomatous polyps in humans. ${ }^{29}$ None of these previous studies have shown any toxic effects caused by HLF. In the present study we, for the first time, investigated the effects of HLF on human GBM cells both in vitro and in vivo.

We performed an in vitro proliferation test on GBM cells (U87MG, NMD, FN) in the presence of different HLF concentrations $(1 \mu \mathrm{g} / \mathrm{ml}, 10 \mu \mathrm{g} / \mathrm{ml}, 100 \mu \mathrm{g} / \mathrm{ml}$, and $1 \mathrm{mg} / \mathrm{ml})$. All tested doses caused growth inhibition of about $30 \%$. We also analyzed the expression of cell cycle regulatory proteins (cyclin D1, cyclin D4) and pERK1/2 in GBM cells treated with HLF. The Western blot analysis showed that, in HLF-treated cells, there was a reduction in the expression of cyclin D1 and/or D4 and a reduction in the protein $\mathrm{pERK} 1 / 2$. These results suggest that the cause 

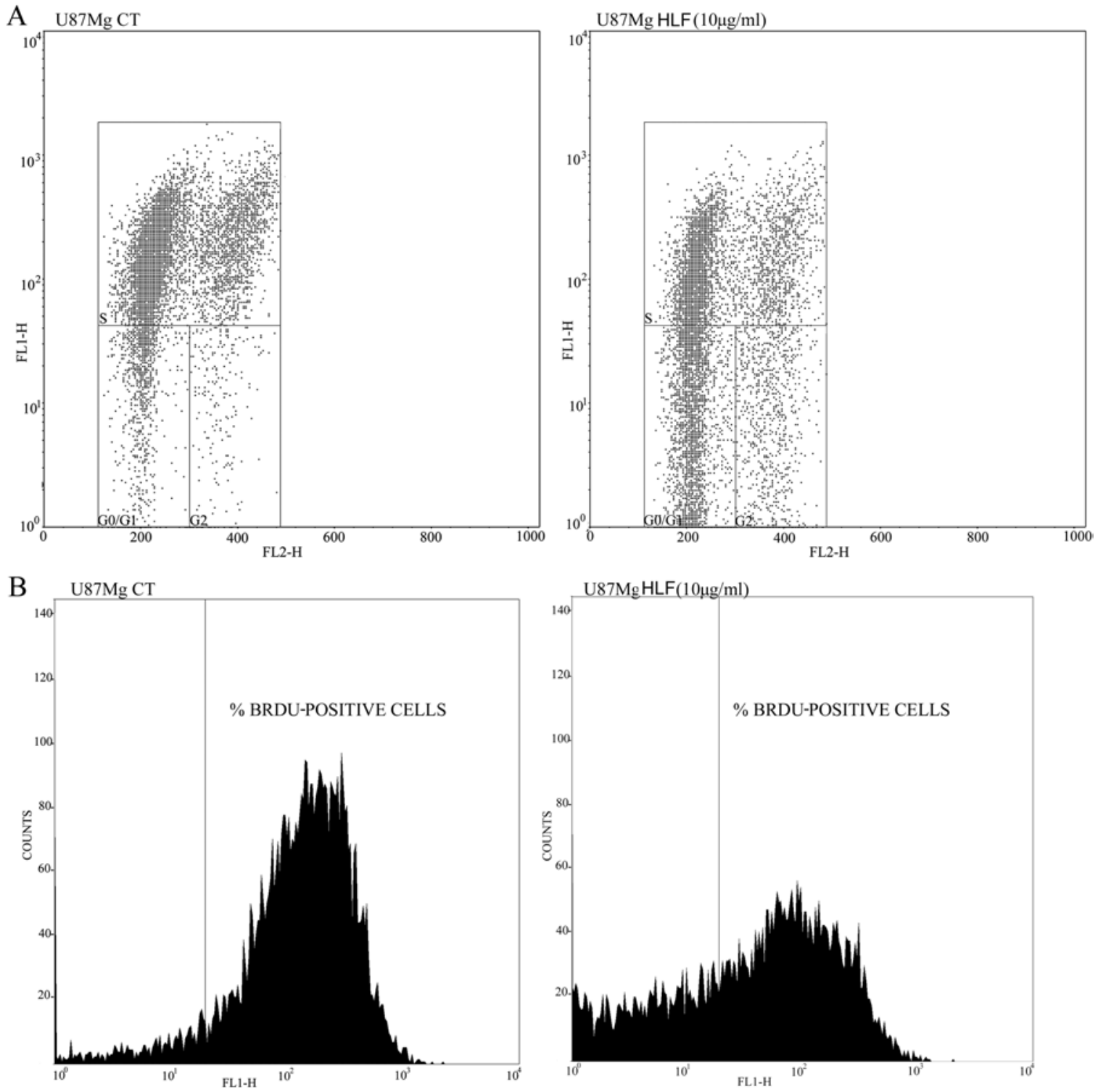

FIG. 5. Lactoferrin inhibits GBM cell growth. A: A representative flow cytometric analysis of propidium iodide staining in U87MG vehicle-treated (left) and HLF-treated (right) cells after 72 hours. As shown, HLF reduced the percentage of cells in the $S$ phase. B: In a representative flow cytometric analysis of BrdU incorporation, histograms represent the percentage of BrdUpositive U87MG cells in a sample treated with vehicle (left) and HLF (right). BrdU peaks show a decrease of incorporation in the sample treated with HLF.

TABLE 1. Results of FACS analysis

\begin{tabular}{lcccc}
\hline \multicolumn{1}{c}{ Sample } & \% Cells in G0/G1 Phase & \% Cells in S Phase & \% Cells in G2 Phase & \% BrdU+ Cells \\
\hline Control $24 \mathrm{hrs}$ & $22.2 \pm 6.4$ & $72 \pm 9.3$ & $6 \pm 2.9$ & $85 \pm 6.7$ \\
\hline HLF $10 \mu \mathrm{g} / \mathrm{ml}, 24 \mathrm{hrs}$ & $44.5 \pm 0.3$ & $41.8 \pm 1.1$ & $14 \pm 0.7$ & $57 \pm 0.5$ \\
\hline Control $48 \mathrm{hrs}$ & $31.7 \pm 2.6$ & $59 \pm 3.6$ & $9.8 \pm 1$ & $77.7 \pm 2.1$ \\
\hline HLF $10 \mu \mathrm{g} / \mathrm{ml}, 48 \mathrm{hrs}$ & $45.8 \pm 0.4^{*}$ & $40 \pm 1.2^{*}$ & $14.2 \pm 0.8$ & $54.4 \pm 0.5 \dagger$ \\
\hline Control $72 \mathrm{hrs}$ & $28.8 \pm 1.1$ & $61.4 \pm 3.6$ & $9.9 \pm 2.6$ & $77.2 \pm 3.2$ \\
\hline HLF $10 \mu \mathrm{g} / \mathrm{ml}, 72 \mathrm{hrs}$ & $42.2 \pm 1.9^{*}$ & $48.7 \pm 5.2$ & $9.4 \pm 3.6$ & $64.9 \pm 4.6$ \\
\hline * Low statistical significance. & & & & \\
$\dagger$ High statistical significance. & & & &
\end{tabular}



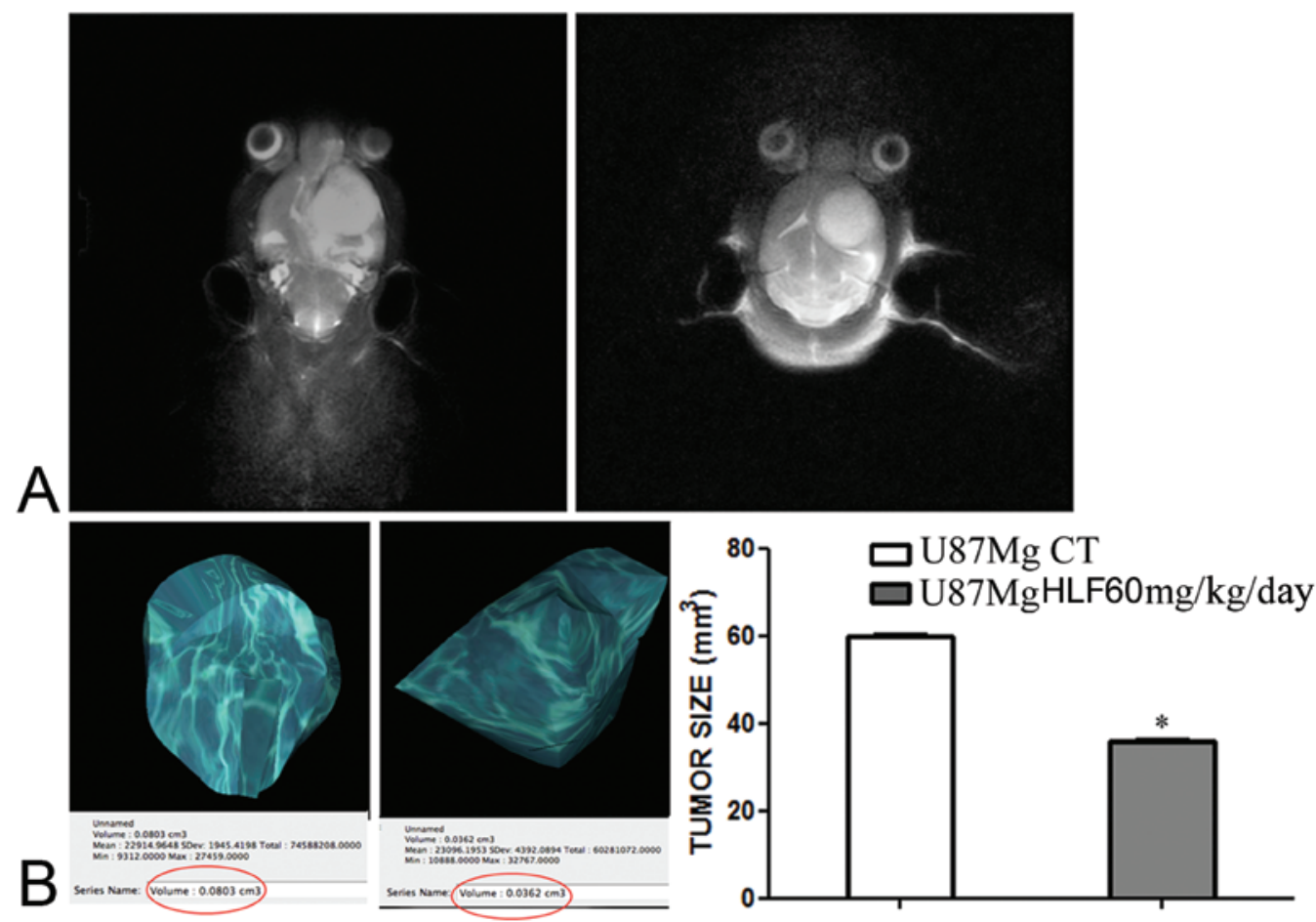

FIG. 6. Lactoferrin treatment inhibits the growth of GBM in vivo. A: Representative MR images from control mice (left) and mice treated with $60 \mathrm{mg} / \mathrm{kg} / \mathrm{day}$ HLF for 12 days (right). Treatment was started 7 days following cell implantation. B: Volumetric reconstruction of tumor originated from unilateral intrastriatal infusion of U87MG cells in control (left) and HLF-treated mice (right). The HLF effects an evident reduction in tumor volume (30\%). Values are means \pm SEM in 10 animals per group. ${ }^{*} p=0.01$ (t-test).
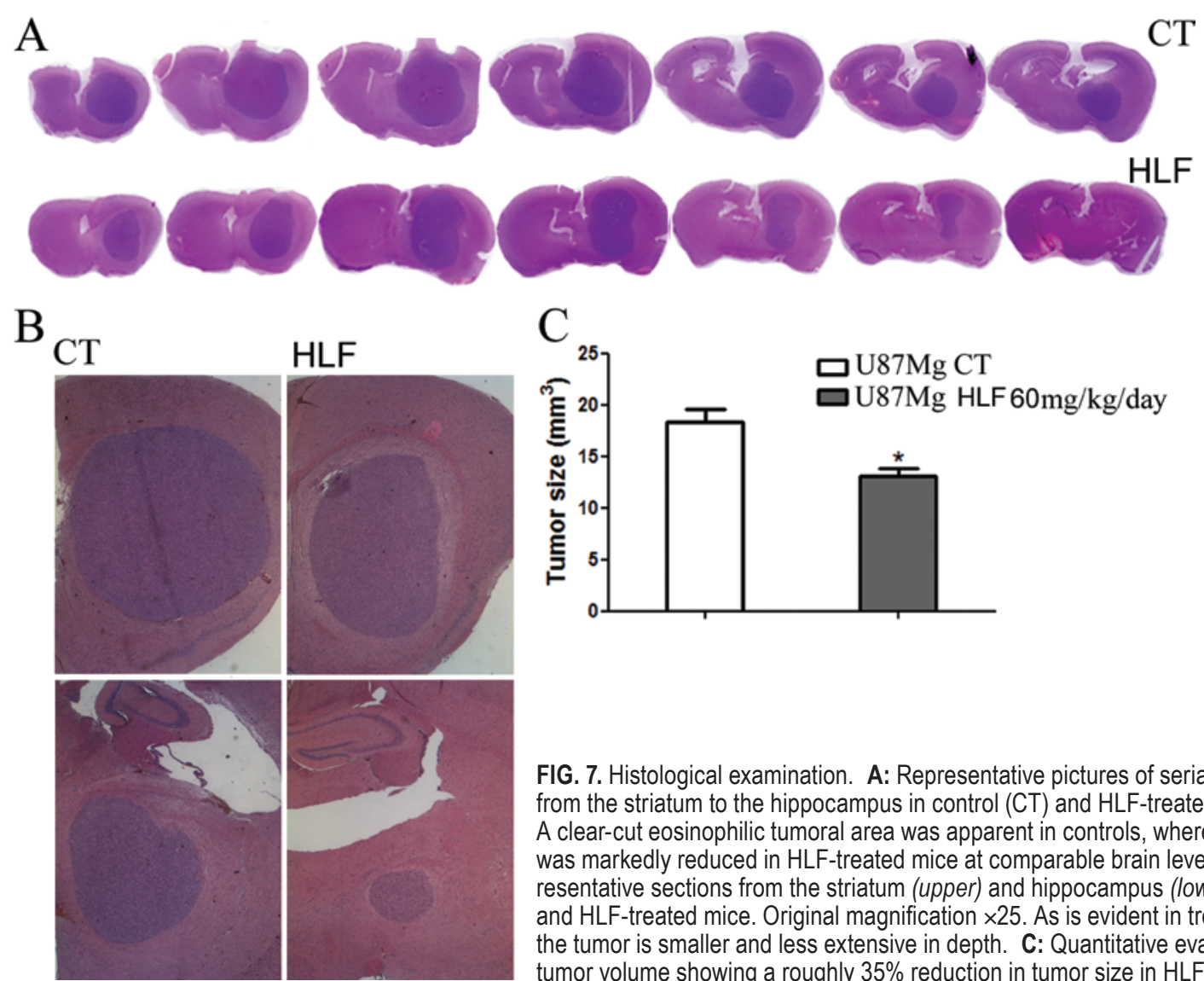

FIG. 7. Histological examination. A: Representative pictures of serial sections from the striatum to the hippocampus in control (CT) and HLF-treated (HLF) mice. A clear-cut eosinophilic tumoral area was apparent in controls, whereas this area was markedly reduced in HLF-treated mice at comparable brain levels. B: Representative sections from the striatum (upper) and hippocampus (lower) in control and HLF-treated mice. Original magnification $\times 25$. As is evident in treated animals, the tumor is smaller and less extensive in depth. C: Quantitative evaluation of tumor volume showing a roughly $35 \%$ reduction in tumor size in HLF-treated mice. 

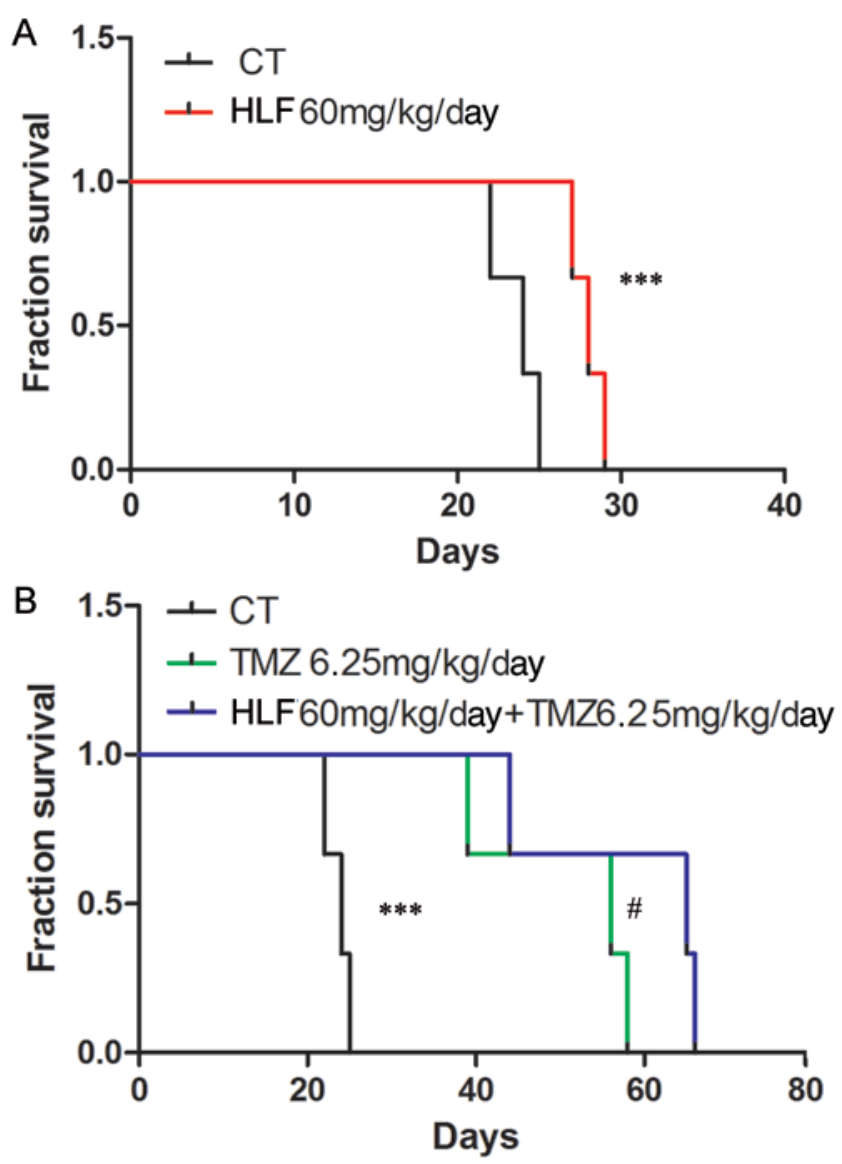

FIG. 8. Synergistic antitumor activities of the combined chemotherapies in vivo. In control mice lethality began at 25 days following tumor implantation. A: Kaplan-Meier curve for HLF (60 mg/kg/day) shows a modest effect on survival. In fact, the curves representing the survival of vehicle-treated $(n=8)$ and HLF-treated $(n=8)$ mice were slightly separated with no overlapping and showed that HLF almost increases the survival of mice by 5 days. B: Kaplan-Meier curve confirms a dramatic effect of TMZ on survival ( 35 days after controls). Lactoferrin administered with TMZ amplifies the effect of chemotherapy. In fact, mice with combined treatment survived 10 days more than mice treated with $\mathrm{TMZ}$ alone.

of the growth inhibition may be a block of the cell cycle in the G0/G1 phase.

This hypothesis was confirmed by FACS analysis: longterm treatment $(24,48,72$ hours) with HLF in U87MG and NMD caused an increase of cells in the premitotic G0/G1 and the G2 phase. However, other mechanisms have been described for the HLF antitumor role, such as the regulation of NK cell activity, ${ }^{5,7}$ modulation of the expression of G1 proteins, ${ }^{6}$ inhibition of human vascular endothelial growth factor A165-mediated angiogenesis, and enhancement of apoptosis. ${ }^{32}$

In our first in vivo experiment, the animals were not allowed to survive beyond the 19 days of tumor growth. However, it is noteworthy that none of the 10 mice that died during observation in both series of experiments belonged to the groups treated with HLF. Mice treated with HLF showed a $30 \%$ reduction in the tumor mass compared with tumor in control mice, as evidenced by reconstruction of MRI volumetric images (Fig. 6). Interestingly, the HLFtreated mice also showed a marked reduction in perile- sional edema on MRI, suggesting a steroid-like effect of HLF reducing the permeability of the blood-brain barrier.

We used the U87MG cell line for in vivo studies because the cells from surgically removed human gliomas, which we had used in vitro, showed limited growth when implanted either subcutaneously or inside the brain of nude mice. We do not have information on the final outcome of brain tumors in mice treated with HLF because the animals were not allowed to survive beyond the 3 weeks of tumor growth. However, it is noteworthy that none of the mice that died during observation in both series of experiments belonged to the groups treated with HLF. In mice treated with HLF (administered for 12 days), there was a reduction in tumor mass compared with tumor in control mice as evidenced by both volumetric analysis of histological sections and reconstruction of volumetric MRI. Magnetic resonance imaging (Fig. 5) confirmed that the reduction in tumor growth was about $30 \%$. It is interesting to note that the MRI in the HLF-treated mice showed reduced edema, making the tumor margins more visible. So HLF could also be used as presurgical treatment to make tumor margins more clear for excision. We expect that systemic treatment with HLF will be even more effective in reducing the growth of primary brain gliomas because the antiproliferative action of HLF was persistent in primary cultures of human gliomas. In a second set of experiments we studied the antiproliferative effects of HLF in combination with TMZ, an alkylating agent commonly used for GBM treatment. These experiments showed that HLF potentiates the effect of TMZ alone, inhibiting growth in all cell lines tested (Fig. 2). The synergism between HLF and TMZ could be used in treating tumors with unmethylated $O^{6}$-methylguanine-DNA methyltransferase (MGMT) that shows a drug-resistant phenotype..$^{10,20}$ To further test the long-term efficacy of HLF and TMZ in vivo, we treated CD1 nude mice carrying an orthotopic GBM xenograft with TMZ alone and with HLF. Mice with combined treatment survived 10 days longer than those treated with TMZ alone.

\section{Conclusions}

In summary, our study confirms the inhibitory effect of HLF in human GBM cells and its potential role in enhancing the efficacy of TMZ without increasing toxicity.

\section{Acknowledgments}

We thank the technicians Emanuele Siravo and Sandro Ottaviano, Department of MRI, Institute Neuromed, for having supported the collection of images. We also thank Ms. Stephania Passarelli, ethics committee of Institute Neuromed, and Prof. Angela Santoni, Rome University, for helpful discussions. We dedicate this paper to Prof. Giampaolo Cantore, our master of science and life, who died on October 5, 2014.

\section{References}

1. Baker EN, Baker HM: Molecular structure, binding properties and dynamics of lactoferrin. Cell Mol Life Sci 62:25312539, 2005

2. Baker EN, Baker HM: A structural framework for understanding the multifunctional character of lactoferrin. Biochimie 91:3-10, 2009 
3. Baveye S, Elass E, Mazurier J, Spik G, Legrand D: Lactoferrin: a multifunctional glycoprotein involved in the modulation of the inflammatory process. Clin Chem Lab Med 37:281-286, 1999

4. Bezault J, Bhimani R, Wiprovnick J, Furmanski P: Human lactoferrin inhibits growth of solid tumors and development of experimental metastases in mice. Cancer Res 54:23102312, 1994

5. Cavestro GM, Ingegnoli AV, Aragona G, Iori V, Mantovani $\mathrm{N}$, Altavilla N, et al: Lactoferrin: mechanism of action, clinical significance and therapeutic relevance. Acta Biomed 73:71-73, 2002

6. Damiens E, El Yazidi I, Mazurier J, Duthille I, Spik G, Boilly-Marer Y: Lactoferrin inhibits G1 cyclin-dependent kinases during growth arrest of human breast carcinoma cells. J Cell Biochem 74:486-498, 1999

7. Damiens E, Mazurier J, el Yazidi I, Masson M, Duthille I, Spik G, et al: Effects of human lactoferrin on NK cell cytotoxicity against haematopoietic and epithelial tumour cells. Biochim Biophys Acta 1402:277-287, 1998

8. de Mejia EG, Dia VP: The role of nutraceutical proteins and peptides in apoptosis, angiogenesis, and metastasis of cancer cells. Cancer Metastasis Rev 29:511-528, 2010

9. Freiburghaus C, Janicke B, Lindmark-Månsson H, Oredsson SM, Paulsson MA: Lactoferricin treatment decreases the rate of cell proliferation of a human colon cancer cell line. $\mathbf{J}$ Dairy Sci 92:2477-2484, 2009

10. Frosina G: DNA repair and resistance of gliomas to chemotherapy and radiotherapy. Mol Cancer Res 7:989-999, 2009

11. Fujita K, Matsuda E, Sekine K, Iigo M, Tsuda H: Lactoferrin modifies apoptosis-related gene expression in the colon of the azoxymethane-treated rat. Cancer Lett 213:21-29, 2004

12. Gifford JL, Hunter HN, Vogel HJ: Lactoferricin: a lactoferrin-derived peptide with antimicrobial, antiviral, antitumor and immunological properties. Cell Mol Life Sci 62:25882598,2005

13. Gundersen HJG, Jensen EB: The efficiency of systematic sampling in stereology and its prediction. J Microsc 147:229-263, 1987

14. Hambardzumyan D, Squatrito M, Carbajal E, Holland EC: Glioma formation, cancer stem cells, and akt signaling. Stem Cell Rev 4:203-210, 2008

15. Iyer S, Lönnerdal B: Lactoferrin, lactoferrin receptors and iron metabolism. Eur J Clin Nutr 47:232-241, 1993

16. Kanwar JR, Palmano KP, Sun X, Kanwar RK, Gupta R, Haggarty N, et al: 'Iron-saturated' lactoferrin is a potent natural adjuvant for augmenting cancer chemotherapy. Immunol Cell Biol 86:277-288, 2008

17. Kozu T, Iinuma G, Ohashi Y, Saito Y, Akasu T, Saito D, et al: Effect of orally administered bovine lactoferrin on the growth of adenomatous colorectal polyps in a randomized, placebo-controlled clinical trial. Cancer Prev Res (Phila) 2:975-983, 2009

18. Levay PF, Viljoen M: Lactoferrin: a general review. Haematologica 80:252-267, 1995

19. Nuijens JH, van Berkel PH, Schanbacher FL: Structure and biological actions of lactoferrin. J Mammary Gland Biol Neoplasia 1:285-295, 1996

20. Ohka F, Natsume A, Wakabayashi T: Current trends in tar- geted therapies for glioblastoma multiforme. Neurol Res Int 2012:878425, 2012

21. Ortensi B, Setti M, Osti D, Pelicci G: Cancer stem cell contribution to glioblastoma invasiveness. Stem Cell Res Ther 4:18, 2013

22. Puddu P, Carollo MG, Belardelli F, Valenti P, Gessani S: Role of endogenous interferon and LPS in the immunomodulatory effects of bovine lactoferrin in murine peritoneal macrophages. J Leukoc Biol 82:347-353, 2007

23. Read RD, Fenton TR, Gomez GG, Wykosky J, Vandenberg SR, Babic I, et al: A kinome-wide RNAi screen in Drosophila glia reveals that the RIO kinases mediate cell proliferation and survival through TORC2-Akt signaling in glioblastoma. PLoS Genet 9:e1003253, 2013

24. Sakamoto N: [Antitumoral effect of human lactoferrin against newly established human pancreatic cancer cell line SPA.] Gan To Kagaku Ryoho 25:1557-1563, 1998 (Jpn)

25. Sánchez L, Calvo M, Brock JH: Biological role of lactoferrin. Arch Dis Child 67:657-661, 1992

26. Steijns JM, van Hooijdonk AC: Occurrence, structure, biochemical properties and technological characteristics of lactoferrin. Br J Nutr 84 (Suppl 1):S11-S17, 2000

27. Stupp R, Mason WP, van den Bent MJ, Weller M, Fisher $\mathrm{B}$, Taphoorn MJ, et al: Radiotherapy plus concomitant and adjuvant temozolomide for glioblastoma. $\mathbf{N}$ Engl J Med 352:987-996, 2005

28. Surawicz TS, Davis F, Freels S, Laws ER Jr, Menck HR: Brain tumor survival: results from the National Cancer Data Base. J Neurooncol 40:151-160, 1998

29. Tsuda H, Kozu T, Iinuma G, Ohashi Y, Saito Y, Saito D, et al: Cancer prevention by bovine lactoferrin: from animal studies to human trial. Biometals 23:399-409, 2010

30. Tung YT, Chen HL, Yen CC, Lee PY, Tsai HC, Lin MF, et al: Bovine lactoferrin inhibits lung cancer growth through suppression of both inflammation and expression of vascular endothelial growth factor. J Dairy Sci 96:2095-2106, 2013

31. Ward PP, Paz E, Conneely OM: Multifunctional roles of lactoferrin: a critical overview. Cell Mol Life Sci 62:25402548, 2005

32. Yoo YC, Watanabe R, Koike Y, Mitobe M, Shimazaki K, Watanabe S, et al: Apoptosis in human leukemic cells induced by lactoferricin, a bovine milk protein-derived peptide: involvement of reactive oxygen species. Biochem Biophys Res Commun 237:624-628, 1997

\section{Author Contributions}

Acquisition of data: Oliva. Drafting the article: Arcella. Critically revising the article: Arcella, Cantore, Frati. Approved the final version of the manuscript on behalf of all authors: Arcella. Statistical analysis: Oliva, Staffieri, Pavone. Study supervision: Arcella. FACS analysis: Alberti. RMI imaging: Grillea, Bartolo. Animal care: Madonna. Brain tumor histology: Giangaspero.

\section{Correspondence}

Antonietta Arcella, IRCCS Neuromed, Località Camerelle, Pozzilli 86077, Italy.email: arcella@neuromed.it. 